Supporting Information

\title{
Nano-folded gold catalysts for electroreduction of carbon dioxide
}

Kam Sang Kwok, ${ }^{1, \ddagger}$ Yuxuan Wang, ${ }^{1, \ddagger}$ Michael C. Cao, ${ }^{3}$ Hao Shen, ${ }^{1}$ Zimin He ${ }^{1}$ Gerald Poirier, ${ }^{5}$ Brain E. McCandless, ${ }^{6}$ Kenneth J. Livi, ${ }^{2}$ David A. Muller, ${ }^{3,4}$ Chao Wang, ${ }^{1,{ }^{*}}$ and David H. Gracias ${ }^{1,2, *}$

${ }^{1}$ Department of Chemical \& Biomolecular Engineering, Johns Hopkins University, Baltimore, Maryland 21218, United States

2 Department of Materials Science and Engineering, Johns Hopkins University, Baltimore, Maryland 21218, United States

${ }^{3}$ School of Applied and Engineering Physics, Cornell University, Ithaca, New York 14853, United States

${ }^{4}$ Kavli Institute for Nanoscale Science, Cornell University, Ithaca, New York 14853, United States

${ }^{5}$ Advanced Materials Characterization Lab, University of Delaware, Newark, Delaware 19716, United States

${ }^{6}$ Institute of Energy Conversion, University of Delaware, Newark, Delaware 19716, United States

*Corresponding authors: dgracias@jhu.edu; chaowang@jhu.edu

\section{Author Contributions}

$\ddagger$ These authors contributed equally

\section{Table of Contents}

1. Details of the experiments and the simulations $\quad$ S2

2. Characteristics of the nano-folded Au catalysts $\quad$ S10

3. X-ray diffraction and STEM studies of the Au catalysts $\quad$ S12

4. Characteristics of the as made and transferred nano-folded $\mathrm{Au} \quad \mathrm{S} 14$

5. Electrochemical measurements of the Au catalysts $\quad$ S16

$\begin{array}{ll}\text { 6. Local } \mathrm{pH} \text { modelling of the Au catalysts } & \mathrm{S} 17\end{array}$

$\begin{array}{ll}\text { 7. References } & \text { S17 }\end{array}$ 


\section{Details of the experiments and the simulations}

\subsection{Preparation of the nano-folded Au catalysts}

Prior to all experiments, we rinsed and dried a heat shrinkable film (Grafix KSF6-C) with isopropanol (IPA) and air. We deposited gold (99.99\% Au) on top of the film by thermal evaporation at a rate of $0.5 \AA / \mathrm{sec}$. To prepare the nano-folded Au catalysts, we cut and clamped the Au film on top of the silicon (Si) wafer and heated it at $200{ }^{\circ} \mathrm{C}$ for 3 mins to form the nanofolded $\mathrm{Au}$ catalyst. We calculated the strain of the uniaxially nano-folded catalysts using the following equation,

$$
\varepsilon_{1 D}=\left|\frac{L-L_{0}}{L_{0}}\right|
$$

where $\varepsilon_{1 D}$ is the strain applied to the Au film, $L_{0}$ is the original length, and $L$ is the length of the Au film after heating.

We calculated the strain of the biaxially strained $\mathrm{Au}-2 \mathrm{D}$ catalysts using the following equation,

$$
\varepsilon_{2 D}=\left|\frac{A-A_{0}}{A_{0}}\right|
$$

where $\varepsilon_{2 D}$ is the strain applied to the Au film, $A_{0}$ is the original area, and $A$ is the area of the Au film after heating.

\subsection{X-ray diffraction measurements}

We obtained the X-ray diffraction patterns (XRD) using a Philips X'Pert Pro diffractometer with the Empyrean Cu LFF tube. We set the X-ray generator at $45 \mathrm{kV}$ and $40 \mathrm{~mA}$, and scanned all the samples from $5^{\circ}$ to $100^{\circ}$ with a step size of $0.02^{\circ}$ and 10 seconds per step.

We obtained the grazing incidence X-ray diffraction (GIXRD) pattern using a D8 instrument (Bruker) with a $\mathrm{Cu}$ source. We measured the samples at a 1 degree incidence angle from $30^{\circ}$ to $70^{\circ}$.

\subsection{Scanning transmission electron microscopy analysis}

Data for STEM images were collected at $300 \mathrm{kV}$ on an FEI Titan Themis CryoS/TEM operating in microprobe STEM mode with an aperture semi-angle of about $3 \mathrm{mrad}$. We collected a diffraction pattern at every scanning point using the Electron Microscope Pixel Array Detector (EMPAD) developed at Cornell University, ${ }^{1}$ resulting in a $4 \mathrm{D}\left(\mathrm{x}, \mathrm{y}, \mathrm{k}_{\mathrm{x}}, \mathrm{k}_{\mathrm{y}}\right)$ dataset. 
To generate the false-colored images, the diffraction patterns were turned into cepstrums ${ }^{2}$ and then run through Principal Components Analysis (PCA). The cepstrum is the Fourier transform of the $\log$ of the diffraction pattern. This transform emphasizes the periodicity in the diffraction pattern and is less sensitive to intensity fluctuations from dynamical diffraction such as thickness fringes or bend contours that cause nonuniform illumination in the diffraction pattern. The false-colored images are color composited from the loadings of the PCA. Similar colored regions indicate similar loadings, thus similar cepstrums, and ultimately similar grains. The colors themselves were arbitrarily chosen and have no inherent meaning.

\subsection{Transfer Au films to arbitrary substrates}

We prepared a two-phase water/toluene solution. The toluene dissolves the PS substrate, and the $\mathrm{Au}$ film is suspended at the water/toluene interface. We removed and added new toluene every few hours over two days. To transfer the Au films to arbitrary substrates, we removed the toluene, lifted the Au films, and transferred them to the receiver substrate. The films could also be wrapped around a needle by manual rolling.

\subsection{Electrochemical measurements}

We measured the electrocatalytic properties of the Au catalysts using a home-built gas-tight electrolysis cell and an Autolab 302 potentiostat (Metrohm). We used a $\mathrm{Hg} / \mathrm{HgSO}_{4}$ electrode (Hach) and a Pt mesh (VWR) as the reference and counter electrode respectively, and a solution of $0.1 \mathrm{M} \mathrm{KHCO}_{3}$ (Sigma Aldrich, $\geq 99.95 \%$ ) as the electrolyte. $\mathrm{CO}_{2}$ was bubbled through a glass frit to the cathode compartment at a constant rate of $20 \mathrm{sccm}$ and purged for 10 minutes prior to each measurement. We assembled the working electrode, by attaching an Ag wire (Alfa Assar) and carbon tape (Nisshin EM) to the Au film, and we covered with Ag wire and carbon tape with Kapton tape (Micronova) to avoid any background signal from the Ag wire. The cathode and anode compartments were separated with an AHO anion exchange membrane (Selemion Inc.), which minimizes the possible transfer of chemical species (e.g. Pt dissolved from the counter electrode, products produced from the cathode) across the cell. We converted all potentials in this work to the RHE scale by $\mathrm{E}(\mathrm{vs} \mathrm{RHE})=\mathrm{E}\left(\mathrm{vs} \mathrm{Hg} / \mathrm{HgSO}_{4}\right)+0.64 \mathrm{~V}+0.0591 \times \mathrm{pH}$, where the $\mathrm{pH}$ for the $0.1 \mathrm{M} \mathrm{KHCO}_{3}$ electrolyte saturated by $\mathrm{CO}_{2}$ is 6.8 . The gas-phase products were measured online using a gas chromatography-mass spectrometry instrument (GC-MS-QP2010SE, Shimadzu). 


\subsection{Carbon monoxide analysis}

We quantified the amount of carbon monoxide (CO) using a GC-MS with a Plot-Q column (Restek). Helium (He) gas was the carrier gas to the GC-MS, and we calibrated the GC-MS using a custom gas mix (Airgas). We sampled the gas samples every ten minutes and recorded six total measurements per value of the potential. We calculated the Faradaic efficiency of $\mathrm{CO}\left(F E \%_{C O}\right)$ using the following equation,

$$
F E \%_{C O}=\frac{p p m_{C O} \times \text { flow rate } \times \frac{n F p_{o}}{R T}}{J_{T o t}} \times 100
$$

In addition, we calculated the partial current densities of $\mathrm{CO}\left(J_{C O}\right)$ using the following equation,

$$
J_{C O}=\frac{p p m_{C O} \times \text { flow rate } \times \frac{n F p_{o}}{R T}}{\text { geometric surface area }}
$$

where $p p m_{C O}$ is the concentration of $\mathrm{CO}$ formation, flow rate $=20 \mathrm{sccm}, n$ is the number of electrons transferred to $\mathrm{CO}_{2}$ to $\mathrm{CO}$ ( $n=2$ for this reaction), $p_{o}=1.013$ bar, $T$ is $273.15 \mathrm{~K}, R$ is gas constant, and $F$ is the Faraday's constant. The geometric surface area in our studies was $0.25 \mathrm{~cm}^{2}$

\subsection{Surface roughness measurement}

We calculated the surface roughness of the Au films by measuring the double-layer capacitance from 0 to $-0.20 \mathrm{~V}$ (vs. RHE) at various scan rates in $0.5 \mathrm{M} \mathrm{KHCO}_{3}$ with purged argon (Ar). We obtained the capacitance of each Au film by calculating the slope of the double-layer versus the scan rate. We calculated the surface roughness using the following equation,

$$
\frac{C_{\text {nano-folded } A u}}{C_{\text {flat } A u}}=\frac{E C S A_{\text {nano-folded } A u}}{\text { Area }_{\text {flat } A u}}=\text { surface roughness }
$$


where $C_{\text {flat } A u}$ is the capacitance of the flat Au, Area $_{\text {flat } A u}$ is $0.25 \mathrm{~cm}^{2}$ in this experiments, $C_{\text {nano-folded } A u}$ is the capacitance of the nano-folded Au catalyst and ECSA $A_{\text {nano-folded } A u}$ is the electrochemical active surface area of the nano-folded Au catalyst.

\subsection{Mass transport model for $\mathrm{CO}_{2}$ electroreduction}

The mass transport model for Au electrocatalysts is based on a previously reported model. ${ }^{3,}$

${ }^{4} \mathrm{As} \mathrm{CO}_{2}$ dissolves in the $\mathrm{KHCO}_{3}$ solution, it readily reacts with water to form carbonic acid,

$$
\mathrm{CO}_{2}(a q)+\mathrm{H}_{2} \mathrm{O} \Leftrightarrow \mathrm{H}_{2} \mathrm{CO}_{3}, \quad K_{1}=2.63 \times 10^{-3}
$$

Carbonic acid is a weak, diprotic acid and can undergo two steps of ionization to form (bi)carbonates,

$$
\begin{aligned}
& \mathrm{H}_{2} \mathrm{CO}_{3} \Leftrightarrow \mathrm{HCO}_{3}^{-}+\mathrm{H}^{+}, \quad K_{2}=2.5 \times 10^{-4} \\
& \mathrm{HCO}_{3}^{-} \Leftrightarrow \mathrm{CO}_{3}^{2-}+\mathrm{H}^{+}, \quad K_{3}=4.69 \times 10^{-11}
\end{aligned}
$$

In alkaline condition $(\mathrm{pH}>7)$, the above reactions involved in the hydrolysis of $\mathrm{CO}_{2}$ can be written as,

$$
\begin{gathered}
\mathrm{CO}_{2}(\mathrm{aq})+\mathrm{OH}^{-} \Leftrightarrow \mathrm{HCO}_{3}^{-}, \quad K_{4}=4.44 \times 10^{7} \mathrm{M}^{-1} \\
\mathrm{HCO}_{3}^{-}+\mathrm{OH}^{-} \Leftrightarrow \mathrm{CO}_{3}^{2-}+\mathrm{H}_{2} \mathrm{O}, \quad K_{5}=4.66 \times 10^{3} \mathrm{M}^{-1}
\end{gathered}
$$

We summarized the initial concentrations and diffusion coefficients of the chemical species in the bulk electrolyte $\left(\mathrm{CO}_{2}(\mathrm{aq}), \mathrm{HCO}_{3}^{-}, \mathrm{CO}_{3}^{2-}, \mathrm{OH}^{-}\right)$in Table $\mathrm{S} 1 .^{3-5}$ The boundary layer between the bulk electrolyte and electrode surface, where the concentration gradient is assumed to be the only factor transferring chemical species between the bulk electrolyte and electrode surface. We assumed that the length of the boundary layer is $100 \mu \mathrm{m}$, corresponding to previously reported assumptions on a flat electrode. ${ }^{3,4}$ The mass balances for $\mathrm{CO}_{2}, \mathrm{HCO}_{3}{ }^{-}, \mathrm{CO}_{3}{ }^{2-}$, and $\mathrm{OH}^{-}$in the boundary layer are described using a series of partial differential equations (PDEs): 


$$
\begin{aligned}
& \frac{\partial\left[\mathrm{CO}_{2}(a q)\right]}{\partial t}=D_{\mathrm{CO}_{2}} \frac{\partial^{2}\left[\mathrm{CO}_{2}(a q)\right]}{\partial x^{2}}-\left[\mathrm{CO}_{2}(a q)\right]\left[\mathrm{OH}^{-}\right] k_{4 f}+\left[\mathrm{HCO}_{3}^{-}\right] k_{4 r} \\
& -r_{C O R}(x) \\
& \frac{\partial\left[\mathrm{HCO}_{3}^{-}\right]}{\partial t}=D_{\mathrm{HCO}_{3}^{-}} \frac{\partial^{2}\left[\mathrm{HCO}_{3}^{-}(a q)\right]}{\partial x^{2}}+\left[\mathrm{CO}_{2}(a q)\right]\left[\mathrm{OH}^{-}\right] k_{4 f}-\left[\mathrm{HCO}_{3}^{-}\right] k_{4 r} \\
& -\left[\mathrm{HCO}_{3}^{-}\right]\left[\mathrm{OH}^{-}\right] k_{5 f}+\left[\mathrm{CO}_{3}^{2-}\right] k_{5 r} \\
& \frac{\partial\left[\mathrm{CO}_{3}^{-}\right]}{\partial t}=D_{\mathrm{CO}_{3}^{-}} \frac{\partial^{2}\left[\mathrm{CO}_{3}^{-}(\mathrm{aq})\right]}{\partial x^{2}}+\left[\mathrm{HCO}_{3}^{-}\right]\left[\mathrm{OH}^{-}\right] k_{5 f}-\left[\mathrm{CO}_{3}^{2-}\right] k_{5 r} \\
& \frac{\partial\left[\mathrm{OH}^{-}\right]}{\partial t}=D_{\mathrm{OH}^{-}} \frac{\partial^{2}\left[\mathrm{OH}^{-}\right]}{\partial x^{2}}-\left[\mathrm{CO}_{2}(\mathrm{aq})\right]\left[\mathrm{OH}^{-}\right] k_{4 f}+\left[\mathrm{HCO}_{3}^{-}\right] k_{4 r} \\
& -\left[\mathrm{HCO}_{3}^{-}\right]\left[\mathrm{OH}^{-}\right] k_{5 f}+\left[\mathrm{CO}_{3}^{2-}\right] k_{5 r}+r_{\mathrm{OH}^{-}}{ }^{\mathrm{COR}}+{\mathrm{rOH}^{-}}{ }^{\mathrm{HER}}
\end{aligned}
$$

where $t$ is time, $x$ is position within the boundary layer, $D$ is the effective diffusion coefficient for a given species and $k$ 's are the rate constants referring to reactions (4) and (5) (" $f$ " and " $r$ " state the forward and reverse, respectively). The rate constants were adopted from the report by Gupta et al, ${ }^{5}$ with $k_{4 f}=5,930 \mathrm{M}^{-1} \mathrm{~s}^{-1}, k_{4 r}=1.34 \times 10^{-4} \mathrm{~s}^{-1}, k_{5 f}=1 \times 10^{8} \mathrm{M}^{-1} \mathrm{~s}^{-1}$ and $k_{5 r}=2.15 \times 10^{4} \mathrm{~s}^{-1}$. In these equations, the generation $\left(r_{\mathrm{OH}^{-}}{ }^{\mathrm{COR}}\right.$ and ${\mathrm{OHH}^{-}}^{\mathrm{HER}}$, for the production of hydroxide from the $\mathrm{CO}_{2}$ reduction and hydrogen evolution) terms are added to account for the electrochemical reactions along the Au catalysts.

We solved the PDEs (6-9) with similar boundary and initial conditions as Gupta et al. ${ }^{5}$ The boundary conditions at the bulk electrolyte interface $(x=0)$, used are, 


$$
\begin{aligned}
{\left[\mathrm{CO}_{2}(\mathrm{aq})\right]_{x=0, t \geq 0} } & =\left[\mathrm{CO}_{2}(\mathrm{aq})\right]_{e q} \\
{\left[\mathrm{HCO}_{3}^{-}\right]_{x=0, t \geq 0} } & =\left[\mathrm{HCO}_{3}^{-}\right]_{e q} \\
{\left[\mathrm{CO}_{3}^{2-}\right]_{x=0, t \geq 0} } & =\left[\mathrm{CO}_{3}^{2-}\right]_{e q} \\
{\left[\mathrm{OH}^{-}\right]_{x=0, t \geq 0} } & =\left[\mathrm{OH}^{-}\right]_{e q}
\end{aligned}
$$

The initial concentrations at the boundary layer are also set to be at equilibrium.

$$
\begin{aligned}
{\left[\mathrm{CO}_{2}(\mathrm{aq})\right]_{x \geq 0, t=0} } & =\left[\mathrm{CO}_{2}(\mathrm{aq})\right]_{e q} \\
{\left[\mathrm{HCO}_{3}^{-}\right]_{x \geq 0, t=0} } & =\left[\mathrm{HCO}_{3}^{-}\right]_{e q} \\
{\left[\mathrm{CO}_{3}^{2-}\right]_{x \geq 0, t=0} } & =\left[\mathrm{CO}_{3}^{2-}\right]_{e q} \\
{\left[\mathrm{OH}^{-}\right]_{x \geq 0, t=0} } & =\left[\mathrm{OH}^{-}\right]_{e q}
\end{aligned}
$$

We consider the electrochemical reactions within the boundary layer's mass balance in eq. (6-9), and set the boundary condition on the electrode ( $x=\delta$, namely at the bottom of Au catalysts) as an impermeable, reflective wall for all species,

$$
D_{A} \frac{\partial[A]}{\partial x}_{x=\delta, t>0}=0
$$

where $A$ represents $\mathrm{CO}_{2}, \mathrm{HCO}_{3}{ }^{-}, \mathrm{CO}_{3}{ }^{2-}$ or $\mathrm{OH}^{-}$.

We assume a first-order dependence of the reaction rate (or $\mathrm{CO}_{2}$ consumption rate) on the $\mathrm{CO}_{2}$ concentration at any given position $x$,

$$
r_{\mathrm{COR}}(x)=k_{\mathrm{COR}}\left[\mathrm{CO}_{2}\right]_{x}
$$

where the rate constant, $k_{C O R}$, is related to the total $\mathrm{CO}_{2}$ consumption rate on the electrode

$$
r_{\mathrm{COR}}{ }^{\text {total }}=\int_{0}^{\delta} r_{\mathrm{CO}_{2}}(x) d x=\int_{0}^{\delta} k_{\mathrm{COR}}\left[\mathrm{CO}_{2}\right]_{x} d x
$$


The total $\mathrm{CO}_{2}$ consumption rate can be derived from the experimentally measured $\mathrm{CO}_{2}$ reduction activity, including the total current density $(j)$ and the Faradaic efficiency (FE) for each product via,

$$
r_{C O R}{ }^{\text {total }}=\left(\frac{j}{F}\right) \sum_{i} \frac{F E_{i} \cdot z_{i}}{n_{i}}
$$

where $z_{i}$ and $n_{i}$ represent the stoichiometric coefficients and electron transfer number for a given product of $\mathrm{CO}_{2}$ reduction (see Table $\mathrm{S} 2$ ).

The generation of $\mathrm{OH}^{-}$is also distributed within the boundary layer and is a result of both $\mathrm{CO}_{2}$ reduction and HER,

$$
r_{\mathrm{OH}^{-}}{ }^{\text {total }}=\mathrm{r}_{\mathrm{OH}^{-}}{ }^{\mathrm{COR}, \text { total }}+\mathrm{r}_{\mathrm{OH}^{-}}{ }^{\mathrm{HER}, \text { total }}
$$

which are further related to the experimentally measured catalytic activities by,

$$
\begin{aligned}
r_{O H^{-}}{ }^{C O R, \text { total }} & =\left(\frac{j}{F}\right) \sum_{i} \frac{F E_{i} \cdot z_{i}}{n_{i}} \\
r_{O H^{-}}{ }^{H E R, \text { total }} & =\left(\frac{j}{F}\right) \frac{F E_{H_{2}} \cdot z_{H_{2}}}{n_{H_{2}}}
\end{aligned}
$$

Here, $z$ and $n$ are the stoichiometric coefficient of hydroxide and the electron transfer number, respectively, for a given reaction shown in Table 2. The distribution of $\mathrm{OH}^{-}$formation from $\mathrm{CO}_{2}$ reduction on $\mathrm{Au}$ films should be consistent with that for $\mathrm{CO}_{2}$ consumption (eq. (19)), namely also proportional to the local $\mathrm{CO}_{2}$ concentration,

$$
r_{\mathrm{OH}^{-}}{ }^{\mathrm{COR}}(x)=k_{\mathrm{OH}^{-}}{ }^{\mathrm{COR}}\left[\mathrm{CO}_{2}\right]_{x}
$$

where the rate constant is given by,

$$
r_{\mathrm{OH}^{-}}{ }^{\mathrm{COR}, \text { total }}=\int_{0}^{\delta} r_{\mathrm{OH}^{-}}{ }^{\mathrm{COR}}(x) d x=\int_{0}^{\delta} k_{\mathrm{OH}^{-}}{ }^{\mathrm{COR}}\left[\mathrm{CO}_{2}\right]_{x} d x
$$


By comparing eq. (26) with eq. (20), we observe that ${k_{\mathrm{OH}^{-}}}^{\mathrm{COR}}$ and $k_{\mathrm{COR}}$ are linearly correlated, with the ratio determined by the stoichiometric coefficients and electron transfer numbers as indicated by eqs. $(21,23)$.

We assumed that the $\mathrm{OH}^{-}$formation from the HER is zero order and independent on the concentrations of $\mathrm{CO}_{2}$ and (bi)carbonate, considering the abundance of water in the electrolyte. The local pH may influence the HER activity, but the variation may not be significant and is not considered in the present model. Although the exact coverage of $\mathrm{CO}_{\mathrm{ad}}$ at a given position in the boundary layer $(0<x<\delta)$ is unknown, the coverage is likely decreases as $x$ increases, along with the drop of $\mathrm{CO}_{2}$ concentration due to the reduction reactions and increase of local $\mathrm{pH}$. Therefore, we assume that the rate of hydroxide formation from HER increases linearly with the depth in the boundary layer,

$$
r_{O H^{-}}{ }^{H E R}(x)=q x
$$

where the coefficient $q$ is given by the experimentally measured HER activity from eq. (24)

$$
r_{O H^{-}}{ }^{H E R, \text { total }}=\int_{0}^{\delta} r_{O H^{-}}{ }^{H E R}(x) d x=\int_{0}^{\delta} q x d x
$$

Given the boundary conditions in eqs. $(10-13,18)$, the initial conditions in eqs. (14-17) and the distribution of reaction rates in eqs. $(19,25,27)$, we can solve the PDEs in eqs. (6-9). This was done in Matlab R2018a using an iterative approach to calculate the rate constant $k_{C O R}$, with the electrode current $(j)$ and Faradaic efficiencies $\left(F E_{i}\right.$ and $\left.F E_{H_{2}}\right)$ at any given potential. 


\section{Characteristics of the nano-folded Au catalysts}

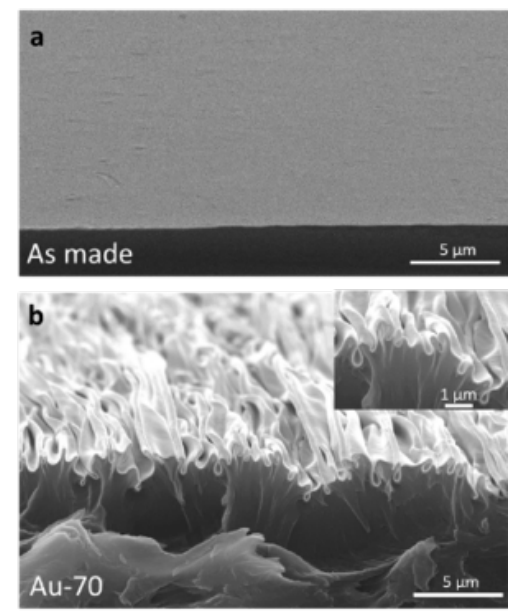

Figure S1. (a) Angled SEM image of the Au-0 catalyst on the PS polymer after evaporation. (b) Angled SEM image of the Au-70 nano-folded catalyst on the pre-strained PS polymer. Residual PS can be seen under the folds after compression indicating that the Au films are attached to the PS and do not delaminate.
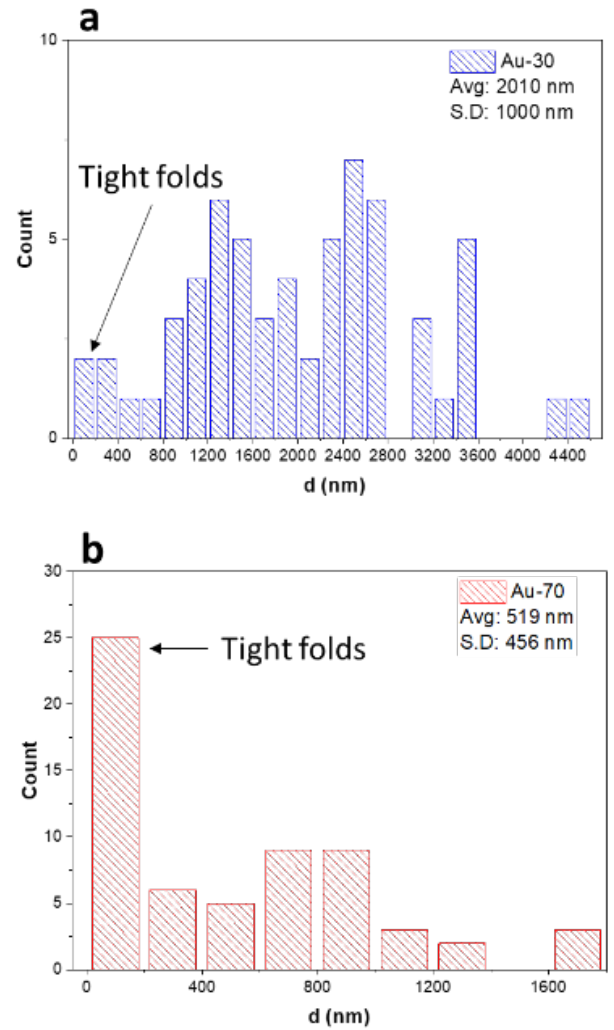

Figure S2. (a) Histogram indicating the distribution of tight and loose folds in the Au-30 nanofolded catalysts. The Au-30 nano-folded catalysts have less than 10\% tight folds. (b) Histogram of the 
distribution of tight and loose folds in the $\mathrm{Au}-70$ nanofolded catalysts. The $\mathrm{Au}-70$ nano-folded catalysts have over $40 \%$ of tight folds. The data plotted is from more than three different samples each.
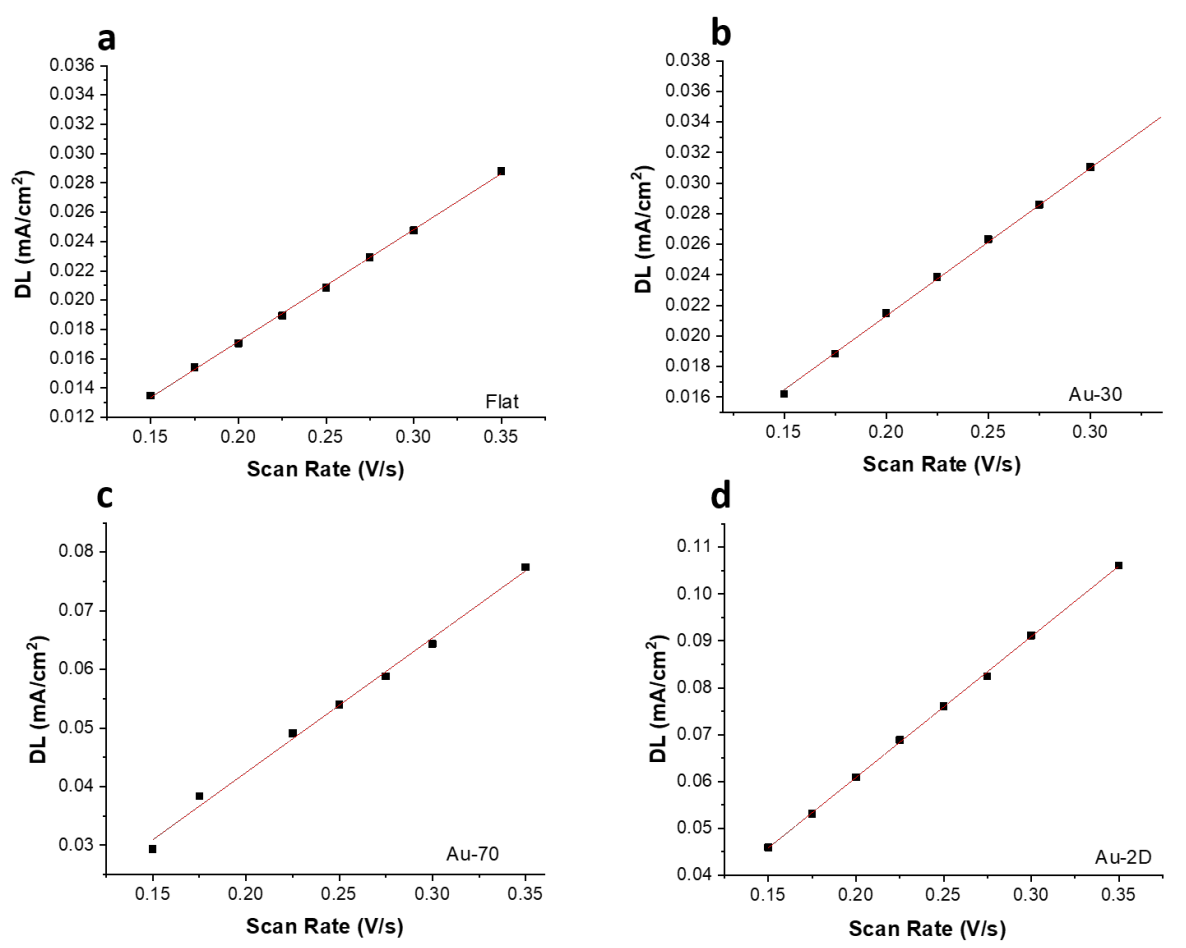

Figure S3. Plots of the double layer capacitance vs scan rates that were used to estimate surface roughness for, (a) Au-0, (b) Au-30, (c) Au-70, and (d) Au-2D. The double layer of Au-2D is the largest among the samples $(\mathrm{Au}-2 \mathrm{D}>\mathrm{Au}-70>\mathrm{Au}-30>\mathrm{Au}-0)$. 


\section{X-ray diffraction and STEM studies of the Au catalysts}

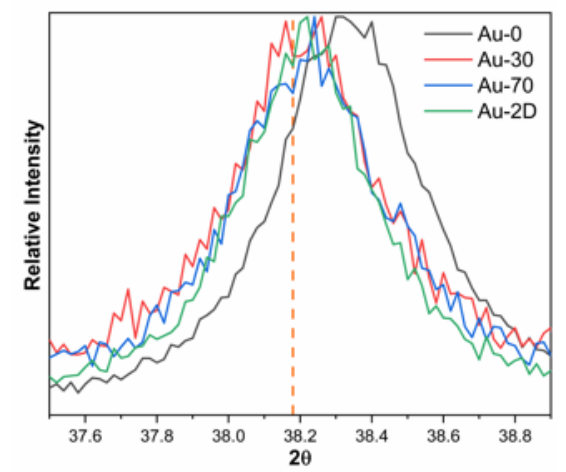

Figure S4. GIXRD of the $60 \mathrm{~nm}$ Au films at 1-degree incident angle. Au-0 was slightly right shifted and less than $0.3 \%$ compressive strain was introduced during deposition. The Au-30, Au-70 and Au-2D after compression showed approximately no strain.
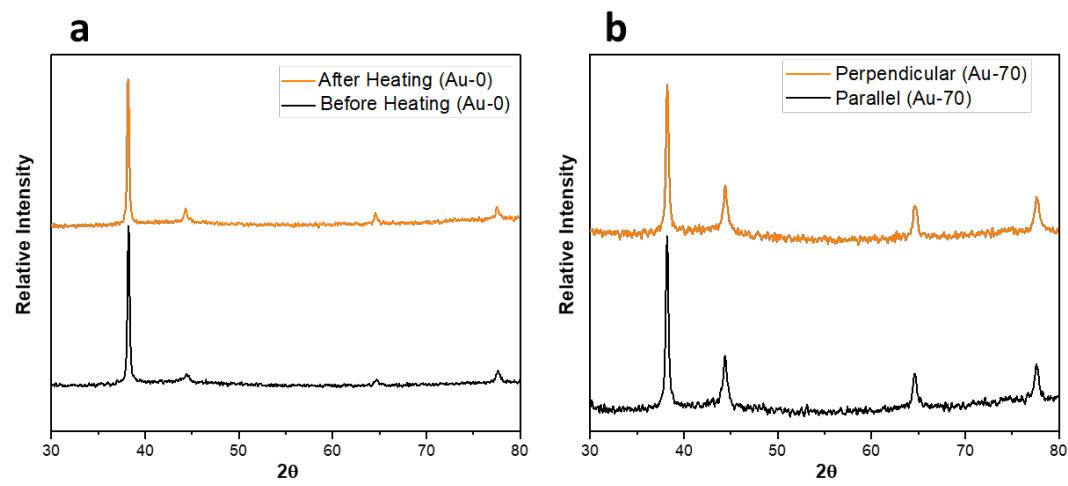

Figure S5. (a) XRD of $60 \mathrm{~nm}$ flat Au-0 on the pre-strained PS substrate before and after heating. No significant change was observed in the flat films on heating indicating that the heating step that is used during processing of the nano-folded catalysts is not responsible for the structural changes observed in Fig. 2a of the main text. (b) XRD of Au-70 nano-folded catalysts with 0 and 90 degree of the X-ray beam.
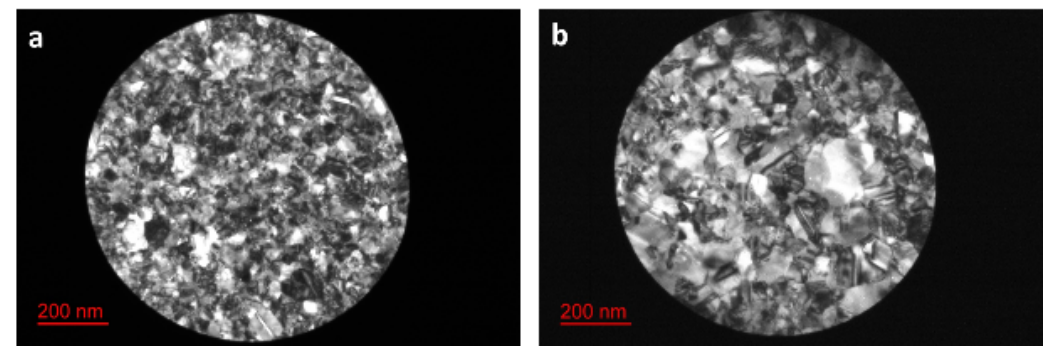

Figure S6. TEM images of $60 \mathrm{~nm}$ of the (a) flat Au-0, and the (b) Au-70 nano-folded catalyst. The images show that the $\mathrm{Au}-70$ nano-folded Au catalyst has larger grains as compared to the flat $\mathrm{Au}-0$ films. 


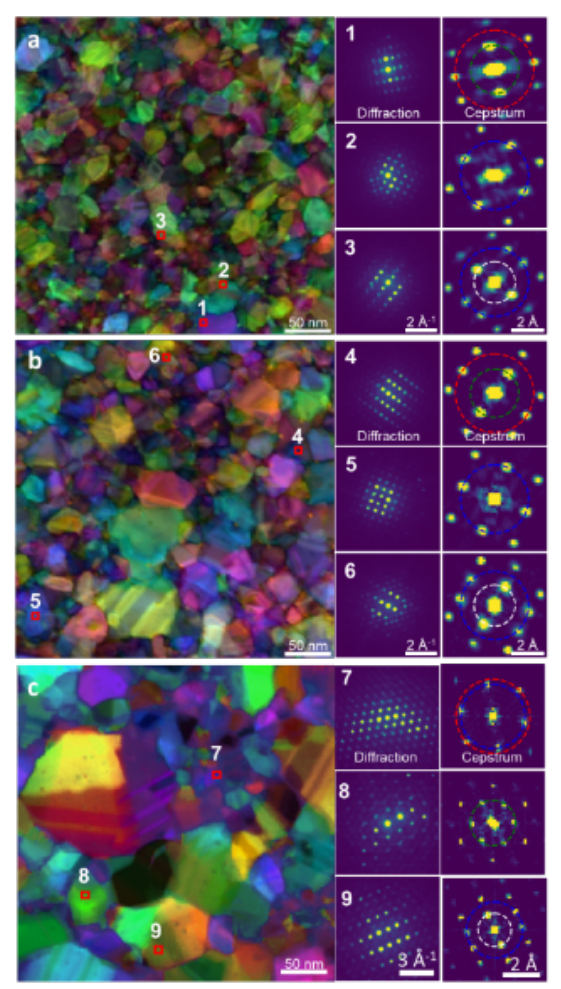

Figure S7. STEM images, diffraction patterns and cepstrums of $30 \mathrm{~nm}$ thick (a) Au-0, (b) Au-70, and (c) $\mathrm{Au}-2 \mathrm{D}$, respectively. The 112 zone (spots 1,4) has planes $\{1 \overline{1} 1\}$ and $\{220\}, 100$ zone (spots 2,5 ) has $\{200\}, 013$ zone (spots 3,6$)$ has $\{200\},\{13 \overline{1}\}$ and $\{\overline{1} 3 \overline{1}\}$. Dashed circles outline the d-spacings present in the cepstrums. Red, blue, green, and white dashed circles represent the 111, 200, 220, and 311 spacings, respectively, consistent with the XRD data 


\section{Characterization of the as made and transferred nano-folded Au catalysts}

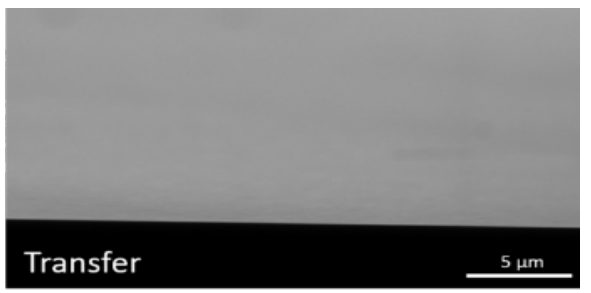

Figure S8. Angled SEM image of the Au-0 catalyst. The image indicates that the film remained flat after transfer from the pre-strained PS polymer to silicon wafer.
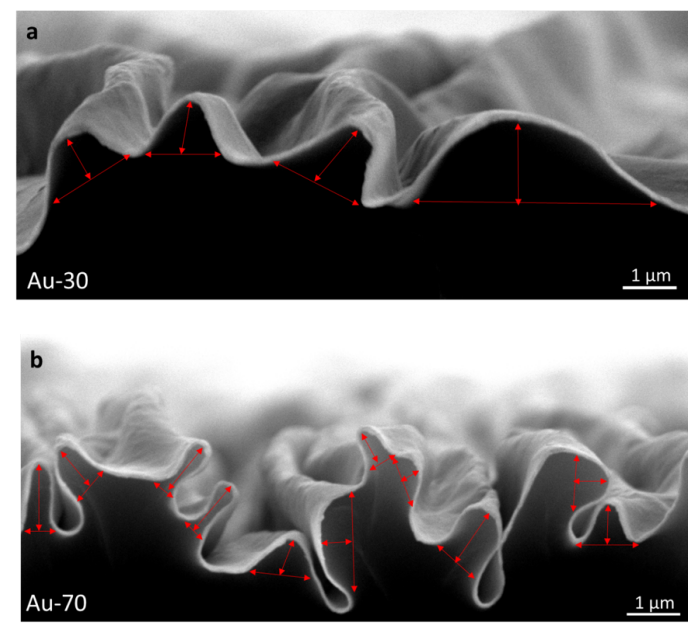

Figure S9. Methodology used to measure the fold dimensions (width and height) from cross-sectional SEM images. Images shown are $\mathrm{Au}-30$ and $\mathrm{Au}-70$ nano-folded catalysts. 

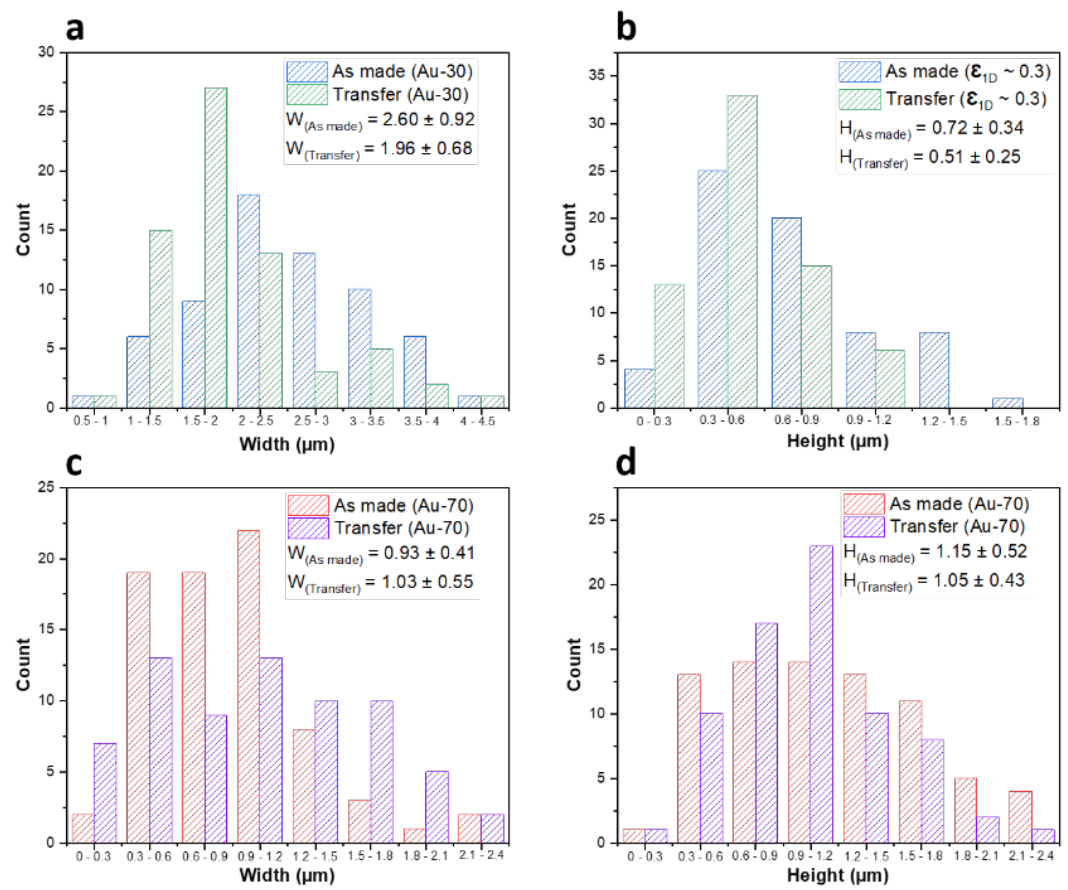

Figure S10. Histograms of width and height of as-made and transferred Au-30 and Au-70 catalysts. (a b) Au-30 catalysts, (c-d) Au-70 catalysts. Both the width and height of the Au-30 catalysts decrease after transfer, and the transferred Au-30 had smaller folds then the as-made Au-30 catalysts. In contrast, the width increased and the height decreased after transfer of the Au-70 catalysts. 


\section{Electrochemical measurements of the Au catalysts}

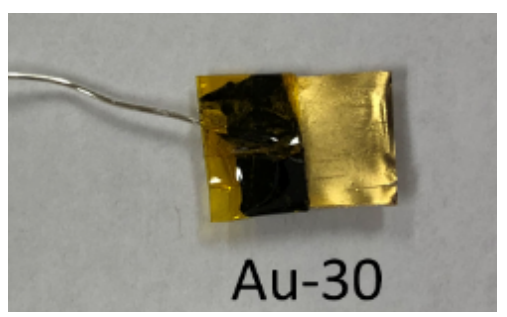

Figure S11. Representative optical image of assembled gold catalysts used for the electrochemical tests.

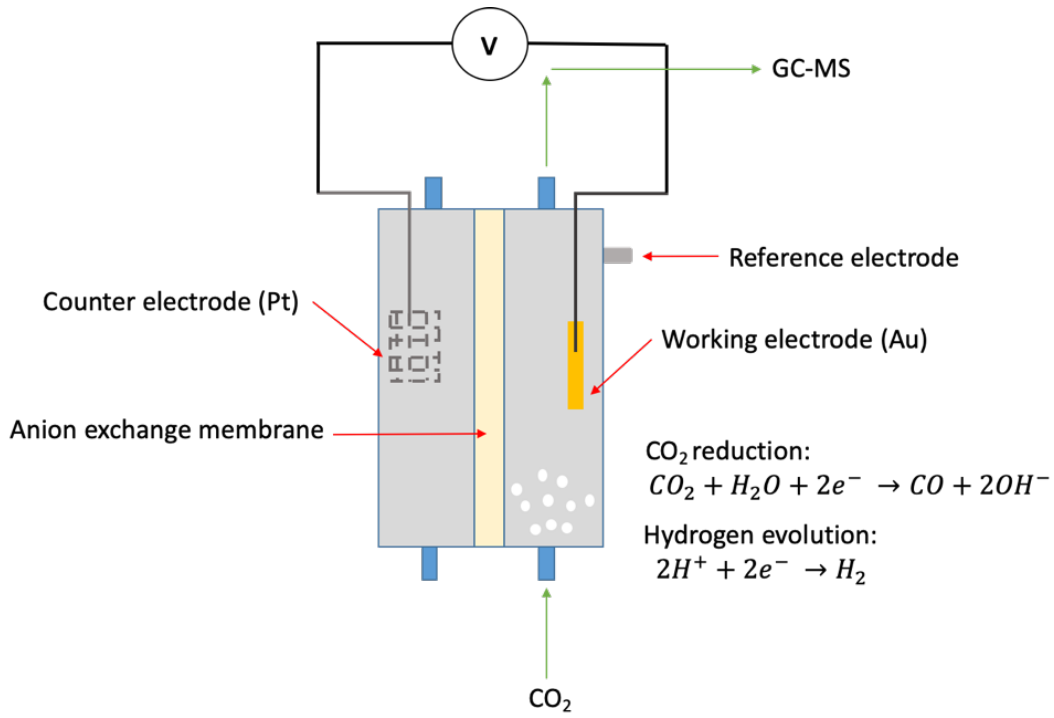

Figure S12. Schematic of the custom-made gas-tight electrolysis cell used in this study. 


\section{Local pH modelling of the Au catalysts}

Table S1. Concentration and diffusion coefficients of chemical species in the bulk electrolyte. ${ }^{3-5}$

\begin{tabular}{ccc} 
Species & $\begin{array}{c}\text { Concentration } \\
(\mathrm{M})\end{array}$ & $\begin{array}{c}\text { Bulk diffusivity } \\
\left(\mathrm{m}^{2} / \mathrm{s}\right)\end{array}$ \\
\hline $\mathrm{CO}_{2}(\mathrm{aq})$ & 0.0342 & $1.91 \mathrm{E}-9$ \\
$\mathrm{HCO}_{3}^{-}$ & 0.099 & $9.23 \mathrm{E}-10$ \\
$\mathrm{CO}^{2-}$ & $3.1 \mathrm{E}-5$ & $1.19 \mathrm{E}-9$ \\
$\mathrm{OH}^{-}$ & $6.6 \mathrm{E}-8$ & $5.27 \mathrm{E}-9$
\end{tabular}

Table S2. Electrochemical reactions and corresponding parameters considered for the mass transport model.

\begin{tabular}{cccc} 
Reactions & $\begin{array}{c}\mathrm{CO}_{2} \\
\text { Stoichiometry } \\
\left(z_{\mathrm{CO}_{2}}\right)\end{array}$ & $\begin{array}{c}\mathrm{OH}^{-} \\
\text {Stoichiometry } \\
\left(\mathrm{z}_{\mathrm{OH}^{-}}\right)\end{array}$ & $\begin{array}{c}\text { Electron } \\
\text { transfer } \\
\text { number } \\
(n i)\end{array}$ \\
\hline $2 \mathrm{H}_{2} \mathrm{O}+2 \mathrm{e}^{-} \rightarrow \mathrm{H}_{2}+2 \mathrm{OH}^{-}$ & - & 2 & 2 \\
$\mathrm{CO}_{2}+\mathrm{H}_{2} \mathrm{O}+2 \mathrm{e}^{-} \rightarrow \mathrm{CO}+2 \mathrm{OH}^{-}$ & 1 & 2 & 2
\end{tabular}

\section{References}

(1) Tate, M. W.; Purohit, P.; Chamberlain, D.; Nguyen, K. X.; Hovden, R.; Chang, C. S.; Deb, P.; Turgut, E.; Heron, J. T.; Schlom, D. G.; Ralph, D. C.; Fuchs, G. D.; Shanks, K. S.; Philipp, H. T.; Muller, D. A.; Gruner, S. M. Microsc. Microanal. 2016, 22 (1), 237-249.

(2) Padgett, E.; Cueva, P.; Holtz, M. E.; Langenberg, E.; Ren, D.; Abruna, H. D.; Schlom, D.; Muller, D. A. Microsc. Microanal. 2018, 24 (S1), 546-547.

(3) Raciti, D.; Mao, M.; Wang, C. Nanotechnology 2017, 29 (4), 044001.

(4) Raciti, D.; Mao, M.; Park, J. H.; Wang, C. J. Electrochem. Soc. 2018, 165 (10), F799-F804.

(5) Gupta, N.; Gattrell, M.; Macdougall, B. J. Appl. Electrochem. 2005, 36 (2), 161-172. 